\title{
DEVELOPMENT AND PRACTICAL USE OF A TOWER INTERIOR SURFACE COATING ROBOT
}

\author{
Masahiko Sawaguchi Bun' ya Ishiguro \\ Yoshinori Kumita Kei Inoue \\ Fujita Corporation
}

WDI Bldg., 13-18 Sendagaya 3-chome

Sibuya-ku Tokyo 151 Japan

\begin{abstract}
This paper deals with the development of a fully automatic tower interior surface coating robot and the results of its application to the spray-coating work at an actual construction site. The coating subjects were the partition walls of reinforced concrete, angular-shaped product silos at a flour mill currently under construction in Tokyo. of the total coating area of about $24,000 \mathrm{~m}^{2}$, an area of about $20,000 \mathrm{~m}^{2}$, excluding the surfaces of hopper and the area immediatly above it, was envisaged to be coated by this robot. Conventionally, coating work at elevated places, as in the jobsite mensioned, has been performed manually with the aid of scaffolding and gonbdola, forcing the workers to be engaged in coating work under closed,harsh working conditions. This coating robot has been developed not only to solve this problem, but also to perform good quality spray-coating, automatically enabling substantial labor saving. This robot system provides a possibility not only of the coating of tower-shaped structures like the silos as in the given example, but also for automated work, such as the coating of exterior wall surfaces of buildings, inspection and maintenance. The necessity for automation of work in the construction industry has increased due to elderly skilled workers and a deficiency of young workers.
\end{abstract}

\section{SUMMARY OF SPRAY WORK TO WHICH THE ROBOT WAS APPLIED}

The plan and sectional elevation are shown in the figures that follow.

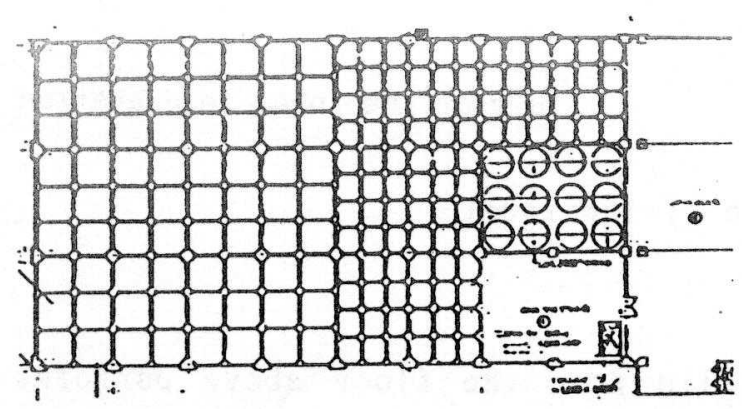

Fig. 1 Plan of product silo

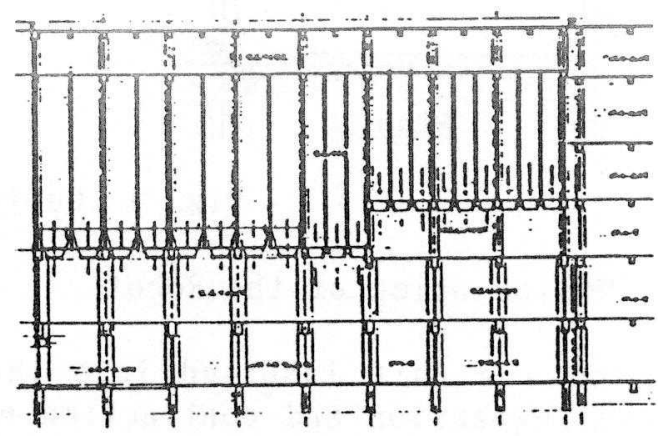

Fig. 2 Sectional elevation of product silo 
The silos with the partition walls to be sprayed by the robot are as outlined below:

- Sectional profile: $3.2 \mathrm{~m} * 3.2 \mathrm{~m} * 17.2 \mathrm{~m}$ deep

$2.4 \mathrm{~m} * 2.1 \mathrm{~m} * 17.2 \mathrm{~m}$ deep

$2.4 \mathrm{~m} * 2.1 \mathrm{~m} * 12.0 \mathrm{~m}$ deep

- Number of silos to be sprayed: 168 units

- Area to be sprayed: Approx. $20,000 \mathrm{~m}^{2}$ of the gross area of $24,000 \mathrm{~m}^{2}$.

- Spraying material : Acryl emulsion paint

\section{OUTLINE OF THE ROBOT}

This robot is composed of (1) robot station, (2) robot proper and (3) spray unit/air supply unit.Fig. 3 outlines the composition. This paper explains the functions and manipulations of the individual components.

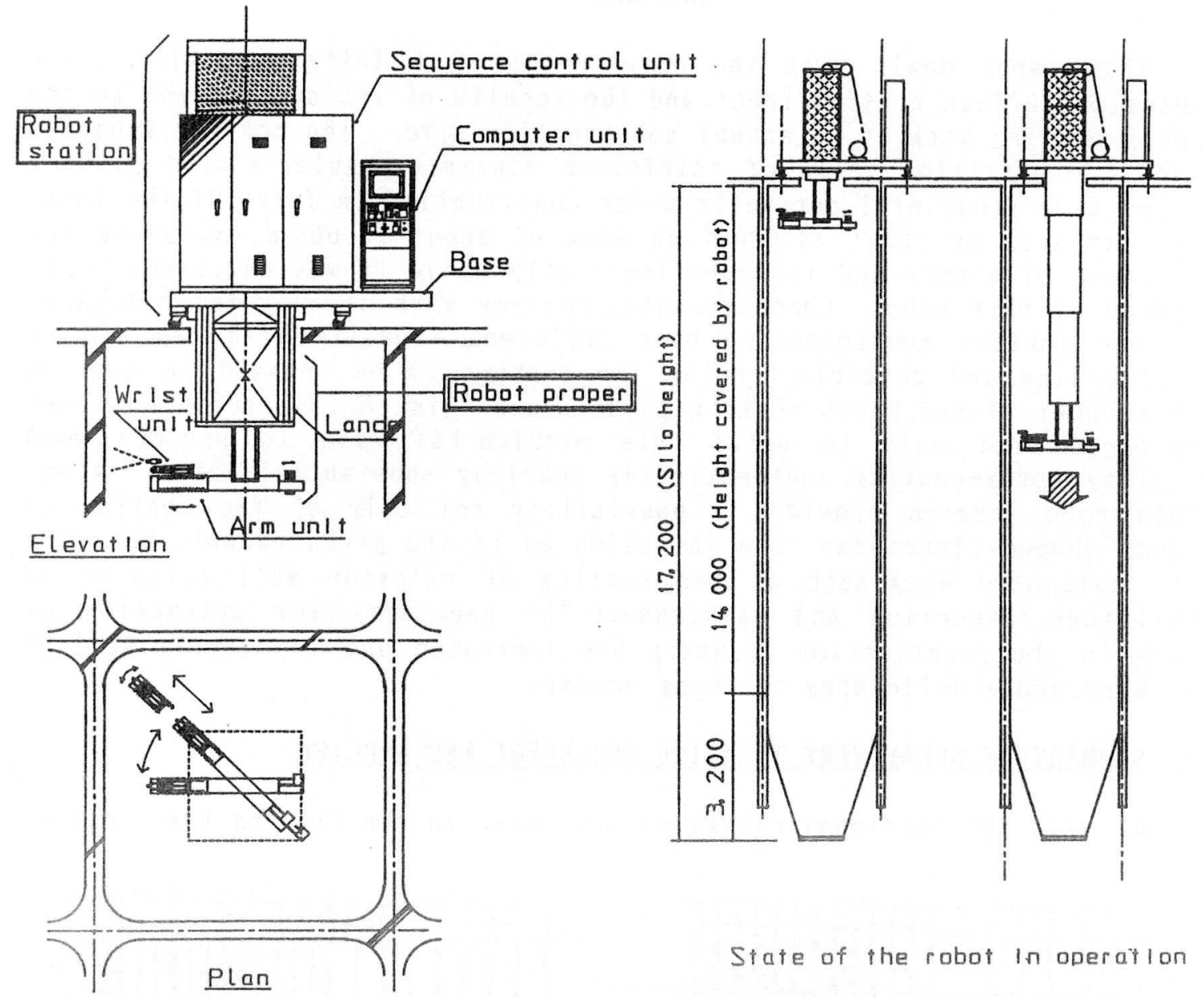

Fig. 3 outline of the robot

2-1 Manipulation of the Robot

The arm unit inserted into the silo from the floor above performs swivel, expansion and contraction movements, as shown in the plan, to move the wrist unit, on which the spray head is later mounted, up to the target position where spraying is to take place. 
The wrist unit then swivels to make the angle between the wall surface and the spray head perpendicular. Following the abovementioned manipulations, the Lance unit descends at a constant speed from the top of the wall to the bottom. During the descent, paint is ejected from the spray head to coat the wall surface. Subsequently, when the Lance unit returns to the top of the wall, the arm unit determines its next target position. For the standard type silo, the robot repeats these manipulations 46 times to complete one cycle of spray work.

These manipulations, except the supply of paint, are all automatically performed by computer.

\section{2 Robot Station}

The robot station is composed of (1) computer unit, (2) sequence control unit, (3) winch and (4) subunits mounted on the base. It supports the robot proper and controls its vertical movement, swivel, expansion/contraction, and the wrist's vertical/horizontal manipulation. Befor migrating horizontally to a second silo, the robot proper is retracted into the robot station. Photo 1 shows the external view of the robot station.

The computer unit incorporates an internal computer to input/output. memorize and represent the various kinds of data, transmit control commands to the sequence control unit. exchange dialogue with the operator, and thereby control the whole robot.

The state of the robot being manipulated can be observed through the display. During automatic operation the computer transmits manipulation commands to the sequencer and monitors the robot manipulation even during manual operation by the operator so that any operational error can be prevented.

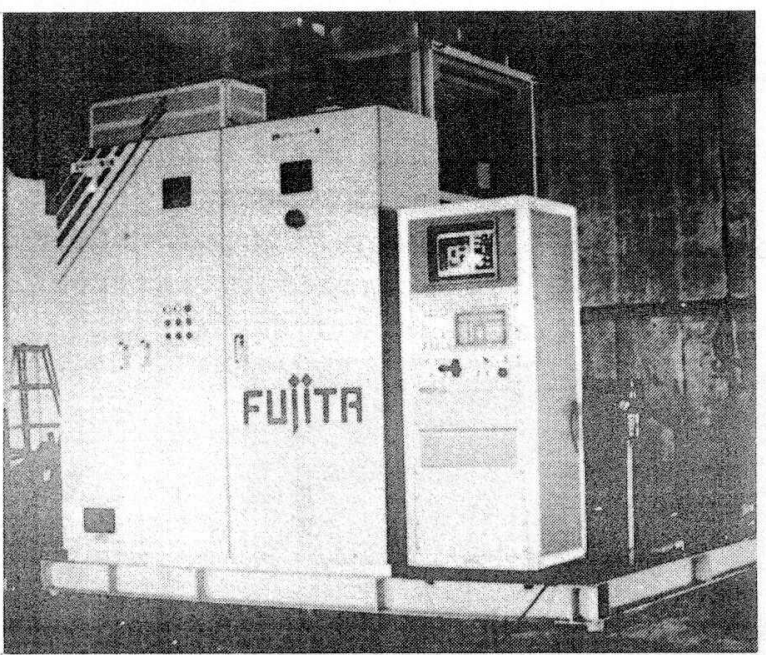

Photo 1 Robot station

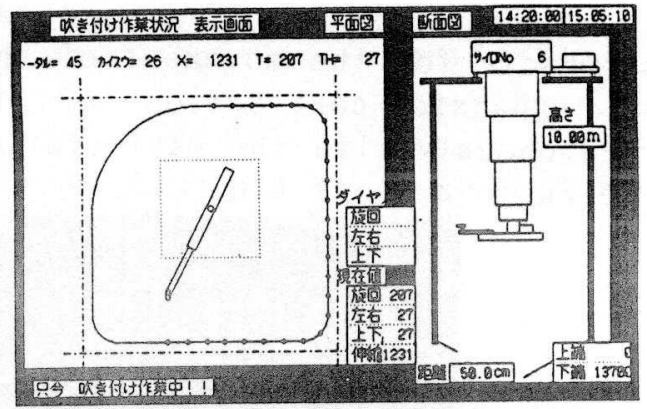

Fig 4 Display of robot's action

\section{3 Robot Proper}

The robot proper is fixed on a base, and is composed of (1) Lance unit, (2) arm unit and (3) wrist unit. The robot proper is the key component moving throughout the silo to perform spray work. The terminal board of 
the control unit accommodated in the robot proper and the inside of the arm unit are structured so that the entry of paint mist is prevented by air purging. Photo 2 shows the robot proper while it is ejecting paint.

(1) Lance unit

The Lance unit is called the multistage telescopic arm position holding unit, and is composed of a 7-stage Lance in this system. Each stage is retracted into the Lance immediately above it. With this system, the moments generated by the swivel or telescopic manipulation of the arm unit and the reactions occurring during spraying are absorbed to prevent slip of the target spray position and thereby stabilize the spray pattern.Fig. 4 shows the section of the Lance unit fixed in place and the state of the arm unit when it is retracted.

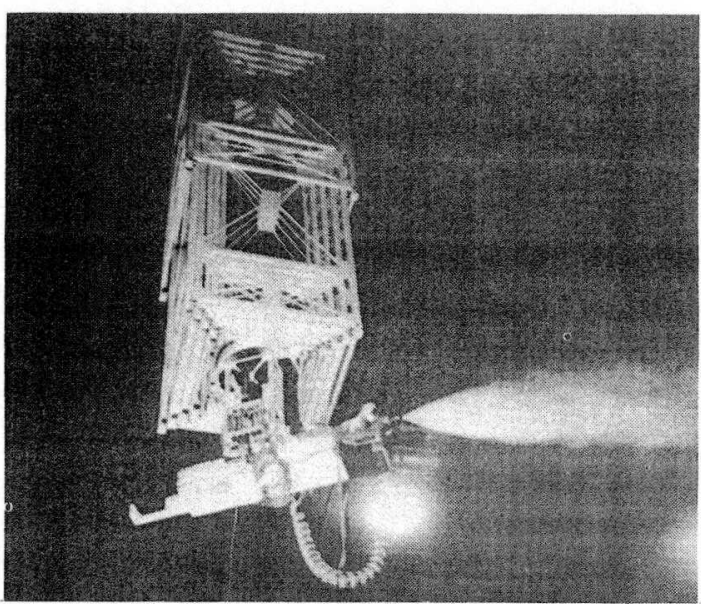

Photo. 2 Robot proper

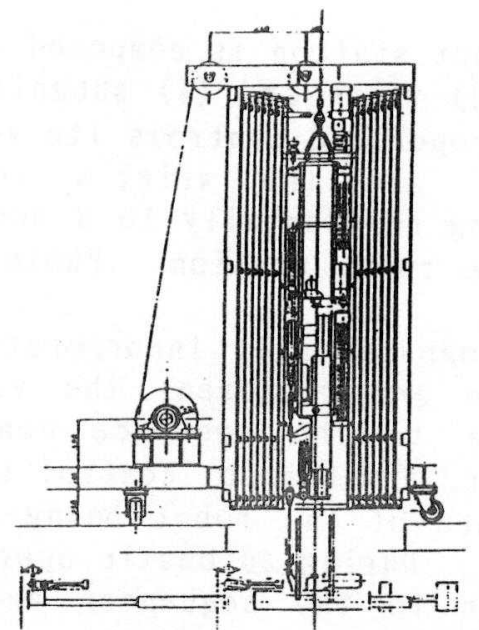

Fig. 4 Section of Lance unit

(2) Arm unit

The arm unit has telescopic and swivel functions and is equipped with a wrist unit at its extremity. The arm expands and contracts with a minimum stroke of $650 \mathrm{~mm}$ and maximum of $1,950 \mathrm{~mm}$ from its center. To compensate for the movement of the center of gravity that results from the expansion/contraction of the arm, a balancer, which moves synchronously with the manipulation of the arm, is attached to its rear side. Photo 3 shows the outside of the arm unit as viewed frombelow.

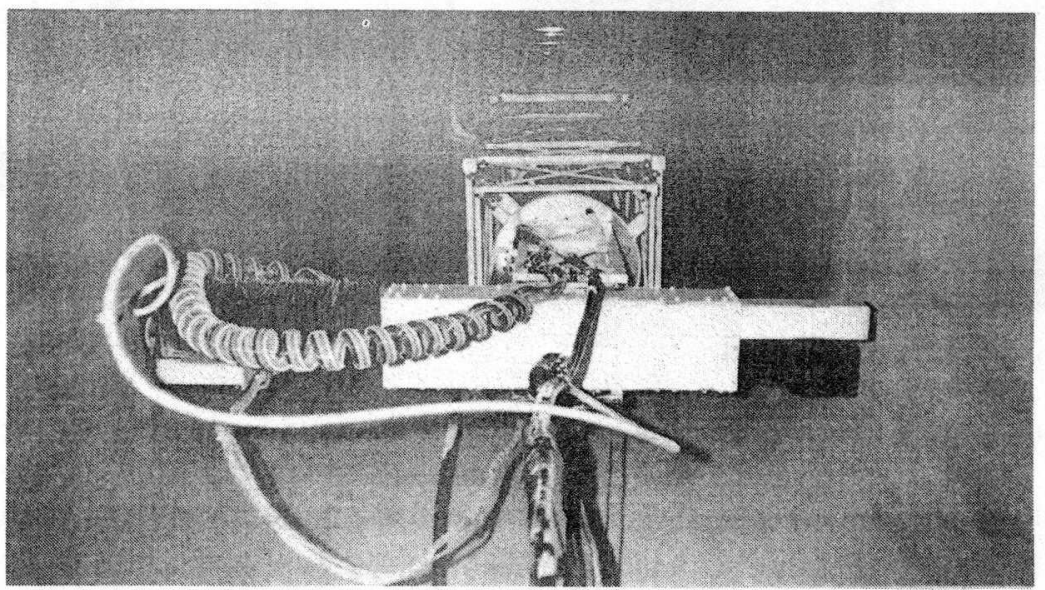

Photo 3 Arm unit 


\section{(3) Wrist unit}

The wrist unit has the freedom of three axes due to a pneumatically driven, artificial muscle. In linkage with the manipulation of the arm, the spray head is held at right angles to the wall surface. Photo 4 shows the wrist unit mounted on the arm unit.

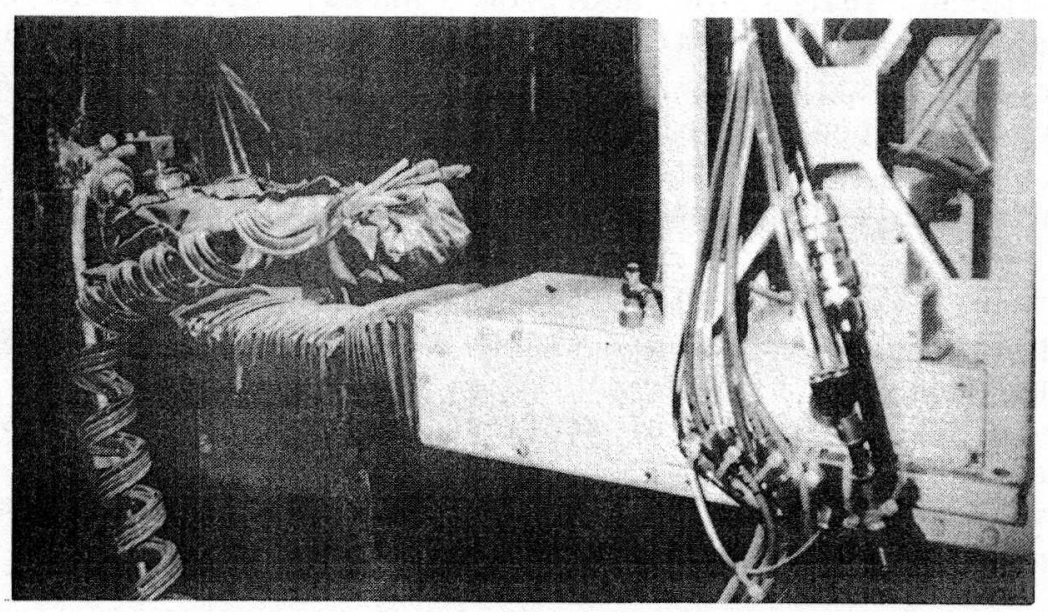

\section{SPECIFICATION}

Photo 4 Wrist unit

The specifications of a tower interior surface coating robot are shown in the following tables.

Table 1 Manipulator

\begin{tabular}{|l|l|}
\hline $\begin{array}{l}\text { Coordinates } \\
\text { Degree of freedom }\end{array}$ & $\begin{array}{l}\text { Polar coordinates } \\
\text { Driving mode }\end{array}$ \\
$\begin{array}{l}\text { Position sensing } \\
\text { mode } \\
\text { inverter control } \\
\begin{array}{l}\text { Positioning } \\
\text { accuracy }\end{array}\end{array}$ & $\begin{array}{l}\text { Rotary encoder } \\
\pm 0.5 m m\end{array}$ \\
\hline
\end{tabular}

Table 2 Lance unit

\begin{tabular}{|l|l|}
\hline Migration & $\begin{array}{l}\text { Multistage telescopic box } \\
\text { box frame }\end{array}$ \\
Migrating speed & $\begin{array}{l}\text { Variable. } \\
\text { (Standard speed:0. } 5 \mathrm{~m} / \mathrm{s})\end{array}$ \\
$\begin{array}{l}\text { Driving mode } \\
\text { Position sensing } \\
\text { mode } \\
\begin{array}{l}\text { Positioning } \\
\text { accuracy }\end{array}\end{array}$ & $\begin{array}{l}\text { Rotary encoder } \\
\pm 5 \mathrm{~mm}\end{array}$ \\
\hline
\end{tabular}

Table 3 Working ability and sensing function

\begin{tabular}{|l|l|}
\hline painting area & $130 \mathrm{~m}^{2} / \mathrm{hr}$ \\
\hline Sensing functions & Ultrasonic sensor (for distance measurement) \\
& Increnometer (for measurement of inclination) \\
& Air pressure detection (contact feeling) \\
& Electric current detection (abnormal driving) \\
& Detection of acceleration (abnormal nigration) \\
Route control & PTP \\
Teaching system & Indirect (numerical input) \\
\hline
\end{tabular}




\section{FEATURES OF THE SYSTEM AND EFFECTS OF ITS INCORPORATION}

Conventionally the spray of paint to the inside wall surface of product silos has been performed manually by means of scaffolding and gondola, increasing the difficulty of the painting work environment in the totally closed space. In addition, manual silo painting work requires a number of skilled painters, giving rise to serious problems in regard to cost, construction time, safety control etc. This spray rob robot has been developed to solve these problems as well as to fully automatically perform quality spray work with greatly reduced labor. The effects of the system's development and incorporation include:

(1) spray work by skilled painters has been eliminated,

(2) uniform painted film thickness can be obtained and quality work performance can be achieved,

(3) the need for the provision of scaffolding for spray work has been eliminated, and

(4) 24-hour work can be performed because of the fully automatic operation of the robot system.

With these features, this spray robot was able to perform the spraying of 168 silo units or approximately $20.000 \mathrm{~m}^{2}$ in the area that was sprayed.

\section{CONCLUSIONS}

For future development, the following applications are under consideration:

(1) application to the finishing of the inside of silo-like structures,

(2) application to the maintenance of silo-like structures.

(3) application to the painting and renovation of building exterior walls,

(4) application to the painting of ship hull walls, and

(5) application to the painting of freighter holds, etc.

The foregoing has outlined the system we have developed recently. However the development of robotized systems for construction work has only just begun. Demands for the technology of migrating robots for construction work will increase in the future. The authors aim to build a more effective system by integrating general robotics with this robot migration technology.

In the case of the robotics introduced to the construction industry, since most subject work is fixed, the robot itself has to move over a considerably larger area than the robots operating at factories. The industrial robots used at construction sites must be capable of being installed and removed with extreme easeas they do not remain as part of the permanent work. 